\title{
A Parameter Classification System for Nonrevenue Water Management in Water Distribution Networks
}

\author{
Dongwoo Jang (iD \\ Department of Civil and Environmental Engineering, Incheon National University, Incheon 22012, Republic of Korea \\ Correspondence should be addressed to Dongwoo Jang; nightray@paran.com
}

Received 28 December 2017; Revised 22 March 2018; Accepted 10 April 2018; Published 6 May 2018

Academic Editor: Dujuan Yang

Copyright (c) 2018 Dongwoo Jang. This is an open access article distributed under the Creative Commons Attribution License, which permits unrestricted use, distribution, and reproduction in any medium, provided the original work is properly cited.

\begin{abstract}
Nonrevenue water (NRW) in a water distribution network is the water lost from unbilled authorized consumption, apparent losses, and real losses compared to the total system input volume. Nonrevenue water is an important parameter for prioritizing water distribution network improvement intervention planning, and it is necessary to identify the affecting parameters. A factor classification system has been developed based on the factors suggested by major institutions and researchers to propose an effective NRW classification system in a water distribution network. The factor classifications used include physical, operational, and socioeconomic factors that could affect NRW. Appropriate standards are required when classifying water main parameters. In this study, three criteria were proposed to create independent factors. The first relates to the properties of the parameter. One determines whether the parameters related to the water network are more suitable for physical, operational, or socioeconomic factors and classifies them into one of these three parameters. Second, one considers data availability and data characteristics taking into account the scope of the coverage area. Third, it must be possible to quantify selected parameter data. Whether the collected data are numerically valid and whether it can be used as a standard for assessment or comparison between regions must be examined. The quantification portion of the qualitative data in managing NRW is important and needs to be used in accordance with reasonable standards. In this study, more factors can be used depending on those selected, and it was found that NRW prediction that reflects regional characteristics is possible.
\end{abstract}

\section{Introduction}

Climate change and population growth have resulted in large requirements of water in domestic, industrial, and agricultural purposes. Water distribution networks are subject to deterioration over time, and this usually leads to difficulties such as decreased capacity of hydraulic facilities, increased volume of water loss, service disruption, and lower water quality. Additionally, the continuing increase in consumer water demand presents additional problems such as low pressure in a pipe network. Migration to urban areas and rapidly growing populations in developing countries has resulted in a vital need for the construction of adequate water systems to distribute water to residents [1-4].

During the early 1990s, no standard term existed to express and evaluate water losses in a water supply system. The International Water Association (IWA) has recognized this problem and established the Water Loss Task Force
(WLTF). The WLTF has examined international best practices and developed a standardized terminology for nonrevenue water (NRW) $[5,6]$.

Nonrevenue water (NRW) is one of the major issues water utilities are facing today, especially in areas with severe water scarcity conditions [7, 8]. NRW includes physical (pipe leaks) and commercial losses (unbilled metered water, unmetered public use, illegal connections, meter error, and water for which payment is not collected) $[9,10]$. The IWA has proposed performance indicators [11-14]. In addition, it has been suggested to avoid the use of a percentage indicator in performance comparison, especially in target areas where there are large differences in consumption per service connection $[15,16]$.

Based on an analysis of the influence of pipe damage on the overall pipe distribution network in determining priorities for improving a water pipeline [17], a systematic replacement and remediation plan has been developed for 
the maintenance of the metropolitan waterworks [18]. Although projects to improve old waterworks are being continuously implemented, it is difficult to avoid economic losses and improve a system's function by enhancing the assessment and accident prevention of old pipes that depend on empirically based judgments [19].

Therefore, advanced study and analysis are required of the factors affecting leaks in decision making to prioritize maintenance of water distribution systems, as well as to identify the physical and operational factors affecting NRW with parameters such as leaks, hydraulic pressure, water quality, and water demand volume [8]. To reduce the NRW, studies analyzing pipe networks, increasing reliability, diagnosing pipe network technology, and evaluating pipe deterioration have been conducted to promote an optimal water distribution system [20-22].

Leak analysis is possible by examining each factor affecting a water distribution system. Yet a water network in a large city is complex and comprises various parameters. To estimate the leak volume, the main water supply network parameters appropriate for the regional characteristics are selected, and an NRW calculation model, developed by statistical methods, will play an important role in operating and managing a water supply network [4].

The NRW index of a water distribution system needs to be proven via relationship with the characteristics of the district metered area and quantifying the influence of related parameters. In districts with severely deteriorated pipe networks, for example, the NRW can be considered high because of many leaks but their extent is not quantified. Unless the correlation between regional characteristics and the NRW is properly identified, NRW management might prove unrealistic and uneconomic even if its ratio is high due to local specificity [4].

Korea's NRW is considered a management performance index of water distribution systems of waterworks operators and municipalities. It can be considered the economic feasibility of a project, suitability of the operational management, and efficiency of investment. A high NRW in terms of economic significance means that the recovery rate compared to the production cost is low [23].

A reduction in NRW is thus essential to maintain sound financial operation of a waterworks business. In operational management, a low NRW ratio indicates appropriate management in water distribution systems; a high NRW usually means problems in operational management of the facility (unmeasured quantities using water meters, leaks, and illegal use).

In addition, investment and expansion of water supply facilities requires a huge budget and determination on appropriate expectation face constraints. Making a decision is difficult on what to prioritize when improving facilities and operations comparing and analyzing the lack of supplied water with the volume of lost tap water. In this case, NRW is expected at driving the project by determining whether to improve or expand the facility's water supply operation. The existing NRW method is based on observational data. Management of leakage is difficult; thus, an analysis of influencing parameters can calculate NRW.
In this study, a classification system for NRW management was suggested using survey results of researchers and international institutions via an analysis of the main parameters of water distribution systems. This study identified parameters for NRW management in water distribution systems. The main content of the research is summarized as follows.

First, a literature survey was conducted using data from domestic and foreign researchers. The relationship of parameters in a water distribution system and NRW, a statistical approach, and ANN studies were reviewed.

Second, a study of parameters related to water distribution systems was conducted. The physical, operational, and socioeconomic factors of water distribution systems were identified and then classified using detailed characteristics for application to NRW management.

Third, a parameter classification process with appropriate standardization was developed avoiding duplication of each parameter's characteristics.

The factor classification system is presented using the aforementioned three steps. The factor classification table was created considering additional quantification such that it can be used for management and estimation of NRW.

\section{Definition of NRW in Water Distribution Systems}

NRW is water that has been produced and is "lost" before it reaches the customer. Losses can be real losses (e.g., via leaks, sometimes also referred to as physical losses) or apparent losses (e.g., via theft or metering inaccuracies) [24-26]. NRW corresponds to water loss due to leaks, commercial problems, and nonbilled consumption such as a lack of water meter precision or mistakes in client databases. In (1), $A_{\mathrm{p}}$ is the volume of water produced per unit time and $A_{\mathrm{b}}$ is the volume of billed water per unit time [1]:

$$
\text { NRW ratio }=\frac{A_{p}-A_{b}}{A_{p}}(\%) .
$$

The definition of NRW is described as the difference between the volume of water input into a water distribution network and the volume billed to customers. NRW has three components as follows [1].

Physical losses comprised of leaks from all parts of the distribution network and overflows at the facility's storage tanks. They can be caused by poor operations and maintenance, a lack of active leak prevention, and poor quality underground assets. Commercial losses are caused by under registration of water meters, errors in data treatment, and the theft of water in various forms.

Unbilled and authorized consumption contains water used for operational purposes or firefighting which is provided free of charge to select consumer groups. Various indicators measure NRW, and essentially all have weaknesses. The generally used indicator is NRW defined as a percentage of water provided. 
TABle 1: Components of water balance $[14,15,29]$.

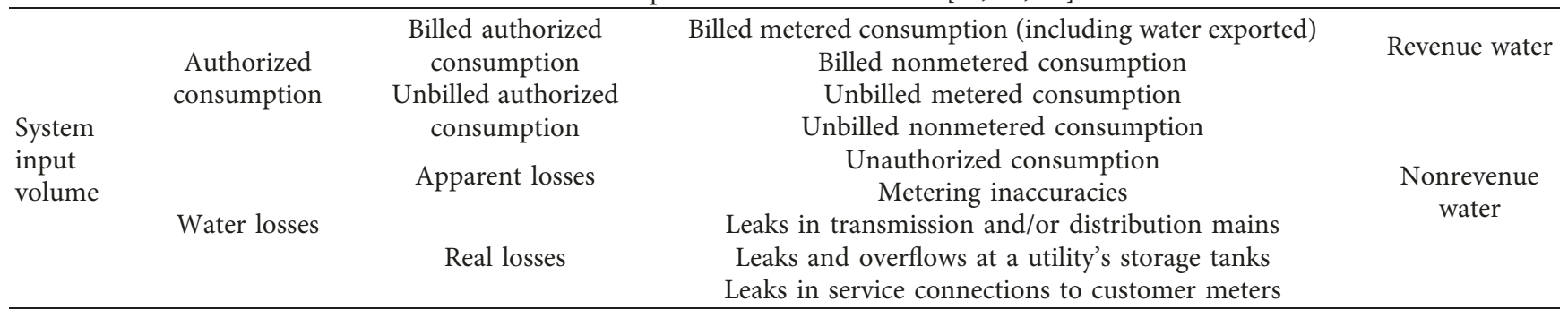

The IWA recommends the use of alternative indices such as water losses per junction and per main length and infrastructure leakage indices [11-13, 24-27]. The latter is a complex index as it also measures pressure in the DMA of water distribution network.

Collecting pressure data at junction for a utility is complicated, however, as measured pressure can vary widely within a piped water supply system. It is thus useful as an index when improving the system performance but cannot be easily used to evaluate network losses between utilities, as averaging such an index for a utility might fail to provide useful data except to reflect an underlying problem [28].

As parameters of water balance in Korea and their definitions are different from those of the IWA, they were rearranged as shown in Table $1[14,15,29]$. Metering and under registration were recalculated, and the remaining amount of the recalculation was added to the ineffective water, which was considered equivalent to the real losses of the IWA's water balance. Water theft and illegal connections are apparent losses of NRW.

Because of the various definitions and deficiency of welldocumented procedures for several parameters (e.g., public use, supplier's official use, and metering under registration), selected data could be inaccurate. Mean pressure and location of water meters were estimated using limited samples, possibly causing data variation [29].

This study focused on physical and operational parameters related to water distribution systems. Physical parameters were considered, and measured data such as the number of leaks were also used for NRW management. Components of water balance in water distribution systems are shown in Table 1 as presented by the IWA [14, 15, 29].

The combined water balance in a network can be calculated using real measured data but doing so in a real water distribution system can be difficult because of the unconstructed district metered area (DMA) and design errors in the water distribution system. In addition, periodic management is an essential element in water distribution systems including identification of leaky pipes, hydraulic pressure management, and proper pump operation.

Because Korea has a detailed standard for its volume of water, NRW calculation using more diverse parameters is necessary. Under the conventional NRW calculation, consideration of physical parameters is needed more than socioeconomic parameters. If physical parameters are only used to calculate NRW, it could reduce the economic cost of measuring NRW and help in selecting the maintenance of DMAs in water distribution systems.

\section{Development of Parameter Classification System}

3.1. Previous Research of Parameter Classification in Water Distribution Systems. In previous research of the main parameters for NRW management, Shinde et al. suggested reliable indicators for waterworks and stable management in water supply systems [7]. Performance indicators (PIs) and quantifiable data (reflecting operational indicators in the water distribution network) were used as indicators related to those used in NRW management. The purpose of PIs is not only to perform statistical analysis but also to provide efficient information to support in decision making. PIs of international organizations are presented in Table $2[7,8]$.

As seen in Table 2, international organizations have recommended similar items. The apparent differences shown in Table 2 are due to the various DMAs for which the indicator system was developed. For example, the World Health Organization (WHO) indicator is suitable for developing countries and districts where costs and services are inadequate.

The IWA components, on the other hand, cover a wide range of indicators to assess every aspect of the system across topographical boundaries and are considered major reference sources in the global water industry [30]. Recent studies have increasingly focused on sustainability indicators [31-34] and those that integrate social and economic aspects of waterworks to ensure long-term service $[8,9]$.

In Table 2, the PIs presented by the IWA include physical and operational factors used in the management of NRW and other water resource, and personal, service quality, and economic and financial indicators were suggested.

For water resources, the efficiency of a water supply can be evaluated by water quality, distance from the water source, and scale of water supply facilities. In terms of quality of service, indicators should be included, but depending on the service system and the water supply facilities such as the reservoir, pressurization facility, water purification plant, and valve facility, a major influence on the manual supply system is observed. This is an essential factor in water loss when managing NRW.

Economic and financial indicators can affect NRW including the tax and water rate system according to the living criteria of residents in the water supply area, and the reconstruction budget of water supply facilities. Thus, this index is also directly related to NRW.

In addition to the aforementioned IWA indicators, the main indicators suggested by the other organizations are 
TABLE 2: PI themes recommended by international organizations $[7,8]$.

\begin{tabular}{|c|c|c|c|}
\hline IWA (2006) & IBNET (2005) & WHO (2000) & WB (1999) \\
\hline $\begin{array}{l}\text { (i) Water resources } \\
\text { (ii) Personnel } \\
\text { (iii) Physical } \\
\text { (iv) Operational } \\
\text { (v) Quality of service } \\
\text { (vi) Economic and } \\
\text { financial }\end{array}$ & $\begin{array}{l}\text { (i) Service coverage } \\
\text { (ii) Water consumption and production } \\
\text { (iii) NRW } \\
\text { (iv) Metering practices } \\
\text { (v) Pipe network performance } \\
\text { (vi) Cost and staffing } \\
\text { (vii) Quality of service } \\
\text { (viii) Billing and collection } \\
\text { (ix) Financial performance } \\
\text { (x) Assets } \\
\text { (xi) Affordability } \\
\text { (xii) Process indicators }\end{array}$ & $\begin{array}{l}\text { (i) User satisfaction } \\
\text { (ii) Community management } \\
\text { (iii) Financial } \\
\text { (iv) Level of service } \\
\text { (v) Materials } \\
\text { (vi) Personnel } \\
\text { (vii) Equipment } \\
\text { (viii) Work control }\end{array}$ & $\begin{array}{l}\text { (i) Coverage } \\
\text { (ii) Water consumption and } \\
\text { production } \\
\text { (iii) Water unaccounted for } \\
\text { (iv) Metering practices } \\
\text { (v) Pipe network performance } \\
\text { (vi) Cost and staffing } \\
\text { (vii) Quality of service } \\
\text { (viii) Billing and collection } \\
\text { (ix) Financial performance } \\
\text { (x) Capital investment }\end{array}$ \\
\hline
\end{tabular}

reviewed. NRW is included as an indicator from the International Benchmarking Network for Water and Sanitation Utilities (IBNET) including service convergence, metering practices, cost and staffing, quality of service, and assets. These are more detailed than the IWA indicators and easier for the user to understand.

WHO has provided indices that take account into customer level rather than user satisfaction and community management. The World Bank provides economic and financial indicators with a weighting factor such as those of water production, water consumption, and water unaccounted for; billing and collection; and capital investment.

The fundamental concept of NRW comprises real (quantity of leaks) or apparent losses (inaccurate metering and illegal use). These losses are direct physical losses, and their management is needed to accurately measure water using meters installed in water distribution systems.

When approximating the technical circumstance of water distribution networks, a qualified analysis of the network's individual components (e.g., separate water pipelines, pressure zones, or measurement districts) is conducted using physical indicators. In terms of the scope and availability of the required supporting analysis, the following physical and operational indicators are recommended [35]:

(a) Pipe age. The service life of a pipe depends on many factors. For each pipe material in the evaluated portion of a water distribution network (pressure zone and water pipeline), consideration of the DMA region in operational experience, as well as an assessment of the theoretical service life of the pipe materials and a comparison to the structure and age of the operated network, is needed. This study chooses the deteriorated pipe ratio for the pipe age indicator. In addition, each DMA network's calculated age of pipes, and its ratio of network data were considered.

(b) Failure fate. Failure evaluation is an important factor for the operational maintenance, repair, and reconstruction planning of a water distribution network. The main indicator for failure analysis in terms of the needs of an evaluated technical circumstance is the failure rate expressed as a number of failures related to the pipe length and unit of time (usually the number of failures per $\mathrm{km}$ per year) and the dynamics of failures. This study suggests the number of leaks as the main parameter $[35,36]$.

(c) Water losses. A number of factors are used to evaluate the water losses, but not all include the effect of a network's technical condition. For estimating the technical condition of a water distribution network, recommended indicators include the unit leakage, infrastructure leakage index (ILI), and economic leakage index (ELI). This study considered water losses using the number of leaks in each DMA.

(d) Pressure in pipe network. From the perspective of the effect of operational pressure on the network's technical condition, a general observation is that a high value of operating pressure is undesirable. Even less desirable is rapid deviation in hydrodynamic pressure each day. The operating pressure value also affects other indicators for evaluating the network's technical condition: water losses, failure rate, and theoretical service life of the pipe material. Water losses caused by leakage, pipe failure, and higher pipe hydraulic pressure can affect energy demands at each junction of a water distribution network. Thus, energy demand is an important parameter explaining the hydraulic pressure of a water distribution system $[4,38]$.

(e) Reliability. Using qualitative and quantitative reliability factors allows identification of the network's critical facilities and their prioritization in reconstruction planning. For each indicator, it is possible to define the processes for its determination, physical dimension, and method of presentation. Each indicator is also a means of monitoring the technical condition of the evaluated distribution network.

In Korea, the Ministry of Environment (MOE) has established the country's main indicators and the classification of water distribution systems. In the assessment of aging and DMAs, factors are classified based on the physical parameters of a water distribution network, and scoring is completed according to weights. According to the Water 
TABLE 3: MOE's evaluation index for deteriorated pipes.

\begin{tabular}{lccc}
\hline \multicolumn{2}{c}{ Indirect evaluation (10 items, 100 points) } & Direct evaluation (12 items, 100 points) \\
\hline $\begin{array}{l}\text { Pipe type (15) } \\
\text { Pipe diameter (3) }\end{array}$ & Soil type (7) & Pipe diameter (27.3) & Thickness of sediment (14.9) \\
Inner pipe coating type (12) & Connection method (5) & Pipe thickness (12.4) & Pipe internal corrosion depth (3.4) \\
Outer pipe coating type (4) & Number of leaks (7) & Coating thickness (8.5) & Internal corrosion circumference (3.2) \\
Elapsed years (37) & Water quality (7) & External corrosion circumference (2.8) & Internal coating management (7.6) \\
& External surface coating anagement (4.4) & Thickness of scale (7.3) \\
Hydraulic pressure (5.0)
\end{tabular}

Source: Waterworks Network Diagnosis Manual [39].

TABLE 4: Classification of main parameters in water distribution systems [4, 8, 36-38].

\begin{tabular}{|c|c|c|}
\hline Provider & Purpose & Parameter \\
\hline $\begin{array}{l}\text { Waterworks } \\
\text { Network Diagnosis } \\
\text { Manual (2007, } \\
\text { Ministry of } \\
\text { Environment) [38] }\end{array}$ & $\begin{array}{l}\text { Water supply pipe } \\
\text { (property data), } \\
\text { deteriorated ratio } \\
\text { Evaluation of small } \\
\text { DMA }\end{array}$ & $\begin{array}{l}\text { Pipe material, pipe type, inner and outer pipe coating types, elapsed years, soil type, } \\
\text { number of complaints of leaks and water quality, pipe diameter, thickness and external } \\
\text { corrosion depth, external corrosion circumference, thickness of scale, and others } \\
\text { Size configuration (loop or resin type), internal and external stagnation parts of DMA, } \\
\text { occurrence of rust, scale attachment of pipe, hydraulic pressure and measurement } \\
\text { facility in DMA, leak measurement management, and number of leaks }\end{array}$ \\
\hline Park, IWA [23] & $\begin{array}{c}\text { Effective parameter } \\
\text { of revenue water } \\
\text { ratio }\end{array}$ & $\begin{array}{l}\text { Fiscal self-reliance ratio, reservoir capacity, water supply population, water price cost } \\
\text { recovery rates, water meter ( } 13 \mathrm{~mm} \text { ) installation rate, amount of daily water supply per } \\
\text { person, and length of deteriorated (more than } 20 \text { years) and water supply pipe } \\
\text { Scale of water supply (population growth rate, population of water supply per number } \\
\text { of demand junctions, and water supply rate), facility scale (total pipe length of DMA, } \\
\text { administrative area, number and capacity of reservoirs, and water meter ( } 13 \mathrm{~mm} \text { ) } \\
\text { installation rate), financial condition (fiscal self-reliance ratio, investment ratios of } \\
\text { maintenance cost compared to expenditures and facility improvement cost compared } \\
\text { to expenditures, replacement rate of DMA pipes per year, and water price cost recovery } \\
\text { rates), and deteriorated facility (length of deteriorated pipe, new installation per year, } \\
\text { and number of leaks per number of demand junctions) }\end{array}$ \\
\hline Jang [40] & $\begin{array}{c}\text { Effective parameter } \\
\text { of revenue water } \\
\text { ratio }\end{array}$ & $\begin{array}{l}\text { Number of leaks and demand junctions, pipe age, hydraulic pressure, and nightly } \\
\text { minimum flow }\end{array}$ \\
\hline Lee $[41]$ & $\begin{array}{l}\text { Rise in revenue } \\
\text { water ratio }\end{array}$ & Replacement rates of DMA, inlet pipe and water meter, and recovery rate of leaks \\
\hline Chung et al. [42] & $\begin{array}{c}\text { Effective parameter } \\
\text { of revenue water } \\
\text { ratio }\end{array}$ & $\begin{array}{l}\text { Population per pipe length in DMA, percentage of homes older than } 21 \text { years, ratio of } \\
\text { apartment units, and installation rate of } 13 \mathrm{~mm} \text { for water meter }\end{array}$ \\
\hline
\end{tabular}

Supply Network Diagnosis Manual [39], the index of the deteriorated pipe is as shown in Table 3.

To assess the deterioration of a pipe, distinguishing indirect evaluation items is possible considering design parameters and numerical data and direct assessment items from measured values via pipeline inspection. Indirect assessment includes physical property elements such as pipe diameter, type, and external observation components such as the number of complaints regarding leaks and water quality.

Direct evaluation objects include pipe data such as pipe thickness, corrosion status, and sediment thickness in the pipeline and hydraulic pressure data generated from the distribution network. The assessment index of the deteriorated pipe ratio is composed of the physical components of pipelines and includes operational components such as hydraulic pressure, which is an appropriate classification system for examining a water distribution system.

Table 4 lists a classification of the parameters in a water distribution system as proposed by the MOE and major domestic studies.
3.2. Establishment of a Parameter Classification System. Adequate standards are mandatory when classifying the parameters of a water distribution network selected from among organizations and researchers. In this study, three criteria were proposed to create independent factors.

The factor classification system was based on the inherent properties of parameters. This study suggested if the parameters related to the water distribution network were more suitable for physical, operational, or socioeconomic parameters and classified them into one of these three groups.

The scope of coverage, data availability, and data characteristics were considered. When data were acquired, regional characteristics could be identified according to whether the boundary data were divided into administrations or DMAs.

Quantification of the data for the selection parameters was possible. Whether the collected data were numerically valid and could be used as a standard for comparison or assessment of regions was examined. If the designated 
TABLE 5: Classification of effective parameters suggested for NRW management [4, 8, 36-38].

\begin{tabular}{|c|c|c|c|}
\hline Primary & & Secondary & Tertiary \\
\hline \multirow{5}{*}{$\begin{array}{l}\text { Physical } \\
\text { parameters }\end{array}$} & Pipe property & $\begin{array}{l}\text { Pipe material, type, inner or outer coating type, elapsed years, mean pipe } \\
\text { diameter, pipe thickness, length of water supply pipe, and metal pipe ratio }\end{array}$ & $\begin{array}{l}\text { Pipe material, mean pipe } \\
\text { diameter, length of water } \\
\text { supply pipe, and elapsed years }\end{array}$ \\
\hline & $\begin{array}{l}\text { Water supply } \\
\text { scale }\end{array}$ & $\begin{array}{c}\text { Amount of daily water supply per person, water supply rate, number } \\
\text { of demand junctions, and reservoir capacity per pipe length of water } \\
\text { distribution systems }\end{array}$ & $\begin{array}{l}\text { Amount of water supply per } \\
\text { number of demand junctions }\end{array}$ \\
\hline & Facility scale & $\begin{array}{c}\text { Reservoir capacity, size, configuration (loop or resin type) and pipe } \\
\text { length of DMA, area of administrative district, and number of } \\
\text { reservoirs }\end{array}$ & $\begin{array}{l}\text { Size and configuration (loop } \\
\text { or resin type) and pipe length } \\
\text { of DMA }\end{array}$ \\
\hline & $\begin{array}{l}\text { Facility } \\
\text { deterioration }\end{array}$ & $\begin{array}{l}\text { Evaluation, ratio and length of deteriorated pipe (age older than } 20 \text { years), } \\
\text { external corrosion depth and circumference of pipe, internal corrosion } \\
\text { depth of pipe and circumference, and new pipe installation per year }\end{array}$ & $\begin{array}{l}\text { Ratio and evaluation of } \\
\text { deteriorated pipe }\end{array}$ \\
\hline & Others & Soil type (chemical classification) & $\begin{array}{l}{ }^{*} \text { Included in evaluation of } \\
\text { deteriorated pipe }\end{array}$ \\
\hline \multirow{3}{*}{$\begin{array}{l}\text { Operational } \\
\text { parameters }\end{array}$} & Leaks & $\begin{array}{l}\text { Leak measurement facility in DMA and management, number of } \\
\text { leaks }(10 \mathrm{~km}) \text {, nightly minimum flow, and leak recovery rate }\end{array}$ & Number of leaks $(10 \mathrm{~km})$ \\
\hline & $\begin{array}{l}\text { Hydraulic } \\
\text { pressure }\end{array}$ & Hydraulic pressure and stagnant part of DMA & Demand energy ratio \\
\hline & Others & $\begin{array}{l}\text { Number of complaints over water quality, self-production rate of tap } \\
\text { water, replacement rates of inlet and DMA pipe, water meter and water } \\
\text { distribution pipe per year, and installation rate of } 13 \mathrm{~mm} \text { water meter }\end{array}$ & $\begin{array}{l}{ }^{*} \text { Included in evaluation of } \\
\text { deteriorated pipe }\end{array}$ \\
\hline \multirow{3}{*}{$\begin{array}{l}\text { Socioeconomic } \\
\text { parameters }\end{array}$} & Population & $\begin{array}{c}\text { Population of water supply per pipe length of water distribution } \\
\text { systems, population growth rate, population of water supply per } \\
\text { number of demand junctions }\end{array}$ & $\begin{array}{l}\text { Population of water supply } \\
\text { per number of demand } \\
\text { junctions and population } \\
\text { growth rate }\end{array}$ \\
\hline & $\begin{array}{l}\text { Financial } \\
\text { condition }\end{array}$ & $\begin{array}{l}\text { Fiscal self-reliance ratio, water price cost recovery rates, and } \\
\text { investment ratio of maintenance cost compared to expenditures and } \\
\text { that of facility improvement cost compared to expenditures }\end{array}$ & $\begin{array}{l}\text { Fiscal self-reliance ratio and } \\
\text { water price cost recovery } \\
\text { rates }\end{array}$ \\
\hline & Others & Percentage of homes older than 21 years and ratio of apartment units & - \\
\hline $\begin{array}{l}\text { Other } \\
\text { parameters }\end{array}$ & - & User satisfaction & - \\
\hline
\end{tabular}

parameters express only qualitative characteristics that cannot be quantified, using them in NRW management is difficult.

The parameter classification system is objectively developed according to the characteristics of each parameter, and this made it possible to consider all the parameters of water distribution networks previously suggested by think tanks and researchers. Parameters related to NRW are examined in regard to physical, operational, and socioeconomic parameters. The effective parameters to NRW are selected according to the developed classification system of main parameters.

Based on these three standards for classification, NRW affecting parameters are classified as listed in Table 5 by using three classifications with no integration or redundancy.

\subsection{Parameter Classification per Data Quantification. Figure 1} shows selected parameters from Table 5 further considering effective NRW parameters from international studies. As shown in Figure 1, the representative parameters for NRW management can be classified as either direct or indirect factors.

Direct factors are physical and operational parameters, and indirect factors are socioeconomic parameters and others. Classification between quantitative and qualitative parameters was also based on data collection considering the data characteristics of selected parameters. Quantitative parameters must be converted by using data quantification standards for each DMA or country.

3.3.1. Direct Factors. Physical factors such as mean pipe diameter, pipe length, number of demand junctions, pipe length per demand junction, amount of water supply per demand junction, and deteriorated pipe ratio have been used in previous studies. If used for NRW management, then the amount of water supply and deteriorated pipe ratio were chosen.

To apply physical parameters to the test bed, a pipe material can be selected an additional parameter as it can affect pipe breakage, pipe leaking, and rehabilitation that will influence the prediction results. Selection of data is necessary such that rehabilitation can be connected to the deteriorated pipe ratio.

Pipe materials such as cast iron and polyvinyl chloride (PVC) can affect the shape and scale in the pipe. Thus, when using a pipe material, a typical classification of the pipe material is required. In a general distribution network system, however, iron pipes such as cast iron or steel pipes are often used, so their use as categorized components can prove difficult depending on the region. 


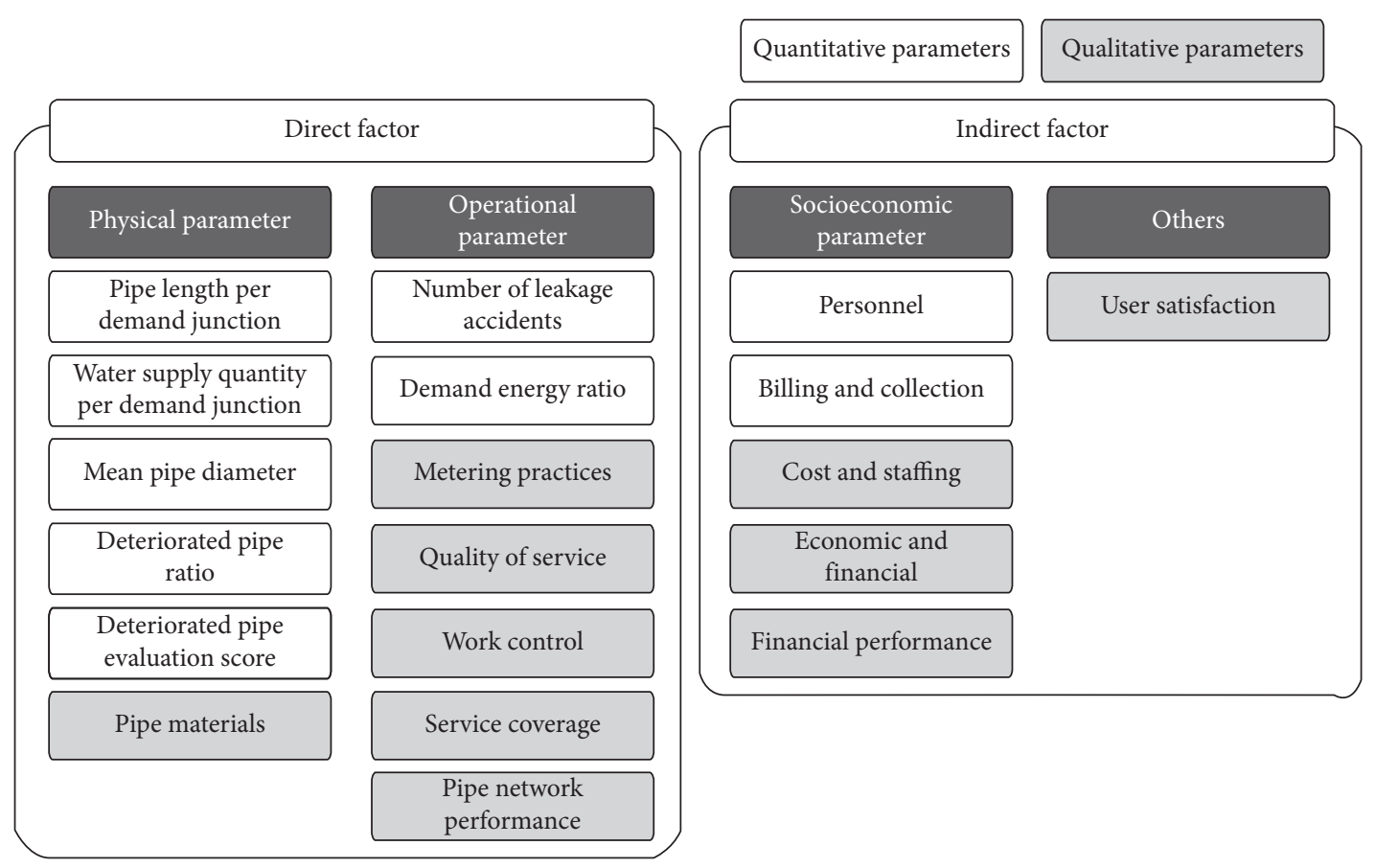

FIgURE 1: Classification of leading parameters for NRW management [4].

Among the direct factors, data on the number of leaks are collected through complaints from residents, thus obtaining reliable data for a specific area can be difficult. The demand energy ratio is a parameter that represents the hydraulic pressure of water distribution networks. It is closely associated with the number of leaks; if high hydraulic pressure is maintained in a water distribution network, the number of leaks will be increased.

The quality of water service, work control, metering practices, service coverage, and pipe network performance are PI factors serving as operational parameters. The quality of service indicates whether the entire procedure of water supply is systematically well established, such as if the water supply system is worked well or the frequency of accidents is low. These conditions can also contain the operation of physical factors such as valve-operating settings, pressurization facilities, optimal maintenance of residual chlorine, and prevention of water quality problems.

When calculating NRW, stable water supply assures water quality, but measures are required when water quality is difficult to maintain. One proposal seeks to preserve residual chlorine concentration by reducing the residence time in the pipeline in which residual chlorine concentration is not maintained compared to regional water-quality criteria.

In urban areas, water quality is not included as a parameter because of the short residence time, but rehabilitation time is longer in a rural area because pipe lengths for water supply are relatively long and the demand is lower than that in an urban area; rural areas are particularly sensitive to water quality parameters such as residual chlorine concentration. In that case, service quality considering water quality parameters can affect NRW.

Metering practice means periodic measurement and accuracy of water meters. Water meter provides physical measurements, but the measured data differ by the type of water meter.

Given its economic efficiency, a mechanical water meter is the most commonly used in Korea. Water meters include dry and wet types. Recently, digital ultrasonic water meters used to improve accuracy but are more costly than analog types and can have power supply problems.

If the parameters of water meter accuracy, periodic measurement, and demand analysis are combined, investigation of NRW characteristics of a target area might become more advantageous. Another crucial task is managing measurement data such that the values measured via a water meter are transformed into a database and a detail analysis can follow.

The factors of work control, pipe network performance, and service coverage are related to the necessary conditions to ensure that the hydraulic pressure in a water network is properly regulated to provide a stable water supply.

Water supply system's managers and operators can moderate the occurrence of leaks by improving the operation of the pipe network. For example, if the hydraulic pressure is high at a junction, the volume of leaked water in the water distribution network increases due to the pressure energy, which leads to a higher NRW.

To maintain an optimal junction pressure, optimal valve operation in the water distribution network and that of the pressurization facility can lower the NRW. Thus, the waterworks operator needs to establish an optimal operating system based on real measurement data. Service coverage varies between densely populated urban areas and rural areas. The network operator must devise an operating plan in which the area of the DMA system should be installed to maintain optimal supply pressure.

Developed artificial neural network (ANN) and multiple regression analysis models based on data of an area where 
a DMA system has been built can be utilized under a condition in which physical and operational element data are collected. Physical parameters are the components that have the greatest influence on distribution network design. Water service convergence is a key element in establishing and operating a network system and can be used for district determination in establishing DMA systems for operational planning and effective NRW forecasting.

3.3.2. Indirect Factors. In this section, we analyzed the indirect factors related to social and economic factors. Because NRW is estimated based on measured data, it is difficult to expect and introduce social and economic parameters. The determination of NRW and physical and operational parameters is influenced by socioeconomic parameters; thus, regional characteristics and socioeconomic factors should be considered when evaluating operational data. This can support the analytical result of NRW.

Indirect factors are classified as socioeconomic factors and others. Socioeconomic factors have a social element representing the population density of a district and can be used to consider the characteristics of urban and rural areas. These parameters differ depending on the grade of urban development. Densely populated areas tend to have shorter water pipe lengths and a lower NRW because of the higher probability of preventing water leaks.

Financial and economic factors indicate the financial strength of a city and the economic life of residents. Developed economies have higher budgets for social infrastructure than those of developing economies, and quality control is performed periodically. Developed economies also are highly likely to use high technology in the operation and management of water distribution systems. These financial and economic factors help us to reduce leaks by reducing their occurrence and optimizing a pipe network's operation.

Financial performance parameters can be connected as an extension of the secondary factor of economic and financial components. An efficient financial system leads to better financial performance that in turn leads to long-term investment and management of water infrastructure and holds an advantage in designing projects such as increasing the revenue/water ratio. Cost and staffing are parameters related to staff works, recruitment, and management fees for waterworks operations. Optimal cost management and staff operations are expected to decrease the occurrence of leaks.

Billing and collection include a factor that determines whether billing is regularly collected. A higher water rate results in a greater advantage, and billing and collection helps in managing infrastructure. Funding is essential for the periodic rehabilitation of existing facilities and introduction of new equipment. In addition, appropriate collection of water fees can be used to invest in water infrastructure. Among indirect factors, user satisfaction shows the grade of optimization in efficient restoration and minimization of operational problems from accidental parameters that can occur in the water distribution networks such as pipeline breakage and leaks. A key task is realizing the indicators because of the potential for personal opinions to be reflected
TABLE 6: Final selected parameters for NRW management $[4,8,36-38]$.

\begin{tabular}{|c|c|c|}
\hline Classification & Parameters & $\begin{array}{c}\text { Application } \\
\text { area }\end{array}$ \\
\hline
\end{tabular}

(i) Pipe material

(ii) Mean pipe diameter

(iii) Pipe length per number

Physical of demand junctions

(iv) Amount of water supply Administrative per number of demand junction area, DMA

(v) Deteriorated pipe ratio (vi) Number of leaks

Operational (vii) Leak recovery ratio

(viii) Demand energy ratio

(ix) Water price cost recovery rates

(x) Investment ratio of maintenance cost to expenditures

Socioeconomic

(xi) Investment ratio of facility improvement

Administrative cost to expenditures

(xii) Population of water

supply per number of demand junctions

(xiii) Fiscal self-reliance ratio

by users and operators. Waterworks system should be developed to quantify user opinions.

\section{Final Parameter Selection for NRW Management}

The final selected parameters via the classification system described in Section 3 are shown in Table 6. The selected parameters are determined based on parameters that can be quantified. Qualitative parameters are classified according to local characteristics. If parameter quantification is possible, qualitative parameters can be used via an additional data conversion process. Based on the parameters selected via the factorization scheme described in Section 3, parameters including subcategorization based on quantifiability were selected.

Among the all parameters described in Section 3.2, the selected physical parameters are mean pipe diameter, pipe material, amount of water supply per number of demand junctions, pipe length per number of demand junctions, and deteriorated pipe ratio. Operational parameters include the number of leaks and the ratio of energy demand and leak recovery.

Among the socioeconomic parameters, parameter classifications and qualitative parameters are selected. As socioeconomic parameters, the population of the water supply per the number of demand junctions, fiscal self-reliance ratio, water price cost recovery rates, and the investment ratio of maintenance costs for facility improvement to total expenditures were determined.

Data acquisition from DMAs and socioeconomic parameters is difficult while physical and operational parameters are applicable in DMAs and administrative 
districts. To apply socioeconomic parameters, the acquisition of statistical data is required and is completed by subdividing DMA data into administrative districts because it depends on measured data classified into administrative districts. Thus, analyses of the specific region where waterworks statistics data are available are necessary for the data collection on physical, operational, and socioeconomic parameters.

\section{Conclusions}

A parameter classification process for NRW management was suggested for water distribution systems. For this purpose, the major water leakage parameters and the factors related to NRW in a water distribution network were investigated. In particular, the process was classified according to the characteristics of the parameters, and quantitative and qualitative parameters were classified to help in NRW management using statistical analysis.

The generation of the parameter classification process was based on the physical, operational, and socioeconomic parameters that can use for NRW analysis. This classification system can be applied to NRW management using the quantified data of selected parameters. The study determined if the parameters related to a water distribution system were more appropriate for physical, operational, or socioeconomic factors and classified them into one of these three categories.

To increase the accuracy of NRW management, socioeconomic parameters such as fiscal self-reliance ratio, population of water supply per demand junction, water price cost recovery rates, investment ratio of facility improvement cost to expenditures, and investment ratio of maintenance cost to expenditures are required. It is anticipated that the NRW accuracy will be improved if additional socioeconomic factors can be expressed by physical and operational parameters.

If the accuracy of NRW prediction is low using the direct factors, it is recommended that NRW prediction be applied using socioeconomic factors. Socioeconomic factors are considered to be helpful in explaining complex NRW phenomena that have limited data acquisition such as administrative districts and DMAs but cannot be explained by physical factors.

Because socioeconomic parameter data in water distribution networks are acquired from administrative districts, a disadvantage is that data acquisition for a DMA is difficult. Thus, one solution for NRW management is a data utilization system for data collection and research that can quantify the classification system of the unquantified data. It is expected that more accurate NRW management will be possible if a data utilization system is activated. In addition, cooperation among administrative districts for data provision should be implemented.

\section{Conflicts of Interest}

The authors declare that they have no conflicts of interest.

\section{References}

[1] J. G. Saldarriaga, S. Ochoa, M. E. Moreno, N. Romero, and O. J. Cortes, "Prioritized rehabilitation of water distribution networks using dissipated power concept to reduce nonrevenue water," Urban Water Journal, vol. 7, pp. 121-140, 2010.

[2] A. Ercumen, J. S. Gruber, and J. M. Colford, "Water distribution system deficiencies and gastrointestinal illness: a systematic review and meta-analysis," Environ Health Perspect, vol. 122, pp. 651-660, 2014.

[3] J. L. Ellen and J. S. Kellogg, "Deficiencies in drinking water distribution systems in developing countries," Journal of Water Health, vol. 3, pp. 109-27, 2005.

[4] D. W. Jang, Estimation of Non-Revenue Water Ratio Using PCA and ANN in Water Distribution Systems, Ph.D. thesis, Incheon National University, Incheon, Republic of Korea, 2017.

[5] M. Malcolm Farley, "Non revenue water-international best practice for assessment, monitoring and control," in Proceedings of the 12th Annual CWWA Water, Wastewater and Solid Waste Conference, Atlantis, Paradise Island, Bahamas, September-October 2003.

[6] R. Frauendorfer and R. Liemberger, The Issues and Challenges of Reducing Non-Revenue Water, Asian Development Bank, Mandaluyong, Philippines, 2010.

[7] V. R. Shinde, N. Hirayama, A. Mugita, and S. Itoh, "Revising the existing performance indicator system for small water supply utilities in Japan," Urban Water Journal, vol. 10, no. 6, pp. 377-393, 2013.

[8] V. Kanakoudis, S. Tsitsifli, and A. I. Zouboulis, "WATERLOSS project: developing from theory to practice an integrated approach towards NRW reduction in urban water systems," Desalination and Water Treatment, vol. 54, no. 8, pp. 21472157, 2015.

[9] A. S. Wyatt, Non-Revenue Water: Financial Model for Optimal Management in Developing Countries, RTI Press, Amman, Jordan, 2010.

[10] D. W. Jang and G. W. Choi, "Estimation of non-revenue water ratio for sustainable management using artificial neural network and z-score in Incheon, Republic of Korea," Sustainability, vol. 9, no. 11, pp. 1-15, 2017.

[11] H. Alegre, W. Hirner, J. M. Baptista, and R. Parena, Performance Indicators for Water Supply Services, IWA Publishing, London, UK, 2000.

[12] H. Alegre, W. Hirner, J. M. Baptista et al., Performance Indicators for Water Supply Services, IWA Publishing, London, UK, 2nd edition, 2006.

[13] H. Alegre, W. Hirner, J. M. Baptista et al., Performance Indicators for Water Supply Services, IWA Publishing, London, UK, 3rd edition, 2017.

[14] A. O. Lambert and W. H. Hirner, Losses from Water Supply System: Standard Terminology and Performance Measure, IWA the Blue Pages, International Water Association, London, UK, 2000.

[15] A. O. Lambert, International Report on Water Losses Management and Techniques, Water Science and Technology: Water Supply, Vol. 2, IWA Publishing, London, UK, 2002.

[16] R. Liemberger, "Do you know how misleading the use of wrong performance indicators can be?," in Proceedings of the IWA Managing Leakage Conference, Lemesos, Cyprus, November 2002.

[17] S. W. Park, T. Y. Kim, K. Y. Lim, and H. D. Jun, "Fuzzy techniques to establish improvement priorities of water 
pipes," Journal of Korea Water Resources Association, vol. 44, no. 11, pp. 903-913, 2011.

[18] C. S. Park, A Case Study on Establishment of Block System for the Increase of Revenue Water in Distribution Systems, Master's thesis, Chonnam National University, Gwangju, Republic of Korea, 2014.

[19] I. C. Park, K. W. Kwon, W. C. Cho, and K. H. Cho, "Study on the decision priority of rehabilitation for water distribution network based on prediction of pipe deterioration," in Proceedings of the Korea Water Resources Association Conference, pp. 1391-1394, Daejeon, Republic of Korea, May 2006.

[20] D. W. Jang, H. S. Park, and G. W. Choi, "Estimation of leakage ratio using principal component analysis and artificial neural network in water distribution systems," Sustainability, vol. 10, no. 3, pp. 1-13, 2018.

[21] H. G. Jo, Study on Influence Factors of Non-Revenue Water for Sustainable Management of Water Distribution Networks, Ph.D. thesis, Incheon National University, Incheon, Korea, in Korean, 2017.

[22] H. G. Jo, G. W. Choi, and D. W. Jang, "Development of the non-revenue water analysis equation through the statistical analysis of main parameter in waterworks system in Incheon city," Crisis and Emergency Management, vol. 12, no. 11, pp. 63-75, 2016, in Korean.

[23] H. S. Park, Study on Korean-ILI Estimation Using the Revenue Water Rate, Master's thesis, Chungbuk National University, Cheongju, Republic of Korea, 2014.

[24] H. E. Mutikanga, S. K. Sharma, and K. Vairavamoorthy, "Assessment of apparent losses in urban water systems," Water and Environment Journal, vol. 25, no. 3, pp. 327-335, 2011.

[25] Wikipedia, Non-Revenue Water, 2018, https://en.wikipedia. org/wiki/Non-revenue_water.

[26] M. Farley, G. Wteth, Z. B. M. Ghazali, A. Istandar, and S. Singh, The Manager's Non-revenue Water Handbook: A Guide to Understanding Water Loses, United States Agency for International Development, Bangkok, Thailand, 2008.

[27] W. Winarni, "Infrastructure leakage index (ILI) as water losses indicator," Civil Engineering Dimension, vol. 11, pp. 126-134, 2009.

[28] C. Van den Berg, The Drivers of Non-revenue Water: How Effective are Non-Revenue Water Reduction Programs?, Policy Research Working Paper Series 6997, The World Bank, Washington, DC, USA, 2014.

[29] S. H. Chung, H. K. Lee, J. Y. Koo, and M. J. Yu, "Characterization of the ratio of revenue water in the 79 cities by principal component analysis and clustering analysis," in Joint Conference of KSWQ and KSWW (The Korean Society of Water and Wastewater and Korean Society of Water and Wastewater), pp. 133-142, February 2004.

[30] V. Kanakoudis and S. Tsitsifli, "Results of an urban water distribution network performance evaluation attempt in Greece," Urban Water Journal, vol. 7, no. 5, pp. 267-285, 2010.

[31] A. A. R. Ioris, C. Hunter, and S. Walker, "The development and application of water management sustainability indicators in Brazil and Scotland," Journal of Environmental Management, vol. 88, no. 4, pp. 1190-1201, 2008.

[32] U. Palme and A. M. Tillman, "Sustainable development indicators: how are they used in Swedish water utilities?," Journal of Cleaner Production, vol. 16, no. 13, pp. 1346-1357, 2008.

[33] T. T. H. Duong, "Urban water management strategies based on a total urban water cycle model and energy aspects-case study for Tel Aviv," Urban Water Journal, vol. 8, no. 2, pp. 103-118, 2011.

[34] A. Milman and A. Short, "Incorporating resilience into sustainability indicators: an example for the urban water sector," Global Environmental Change, vol. 18, no. 4, pp. 758-767, 2008.

[35] L. Tuhovčák, M. Svoboda, Z. Sviták, and K. Tothova, The Technical Audit of Water Distribution Network Using the Different Leakage Indicators, IWA Leakage, London, UK, 2005.

[36] V. K. Kanakoudis and D. K. Tolikas, "The role of leaks and breaks in water networks-technical and economical solutions," Aqua, vol. 50, pp. 301-311, 2001.

[37] V. K. Kanakoudis, "A troubleshooting manual for handling operational problems in water pipe networks," Aqua, vol. 53, pp. 109-124, 2004.

[38] S. Tsitsifli, V. Kanakoudis, C. Kouziakis, G. Demetriou, and S. Lappos, "Reducing non-revenue water in urban water distribution networks using DSS tools," Water Utility, vol. 16, pp. 25-37, 2017.

[39] Ministry of Environment, Waterworks Network Diagnosis Manual, Ministry of Environment, Sejong City, Republic of Korea, 2007.

[40] J. K. Jang, "A Study on Priority Estimation Model of Water Distribution System Maintenance Using the Non Revenue Water Reduction Factors," Master's thesis, University of Seoul, Republic of Korea, 2012, in Korean.

[41] J. M. Lee, "A Study on Cost Benefit Analysis and Leakage Reduction Prediction Model for Revenue Water Ratio Enhancement Project," Master's thesis, University of Seoul, Republic of Korea, 2013, in Korean.

[42] S. H. Chung, H. K. Lee, J. Y. Koo, and M. J. Yu, "Characterization of the Ratio of Revenue Water in the 79 Cities by Principal Component Analysis and Clustering Analysis," in Proceedings of Korean Society of Water \& Wastewater, Daejeon, Republic of Korea, 2014, in Korean. 


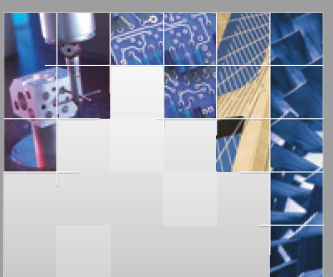

\section{Enfincering}
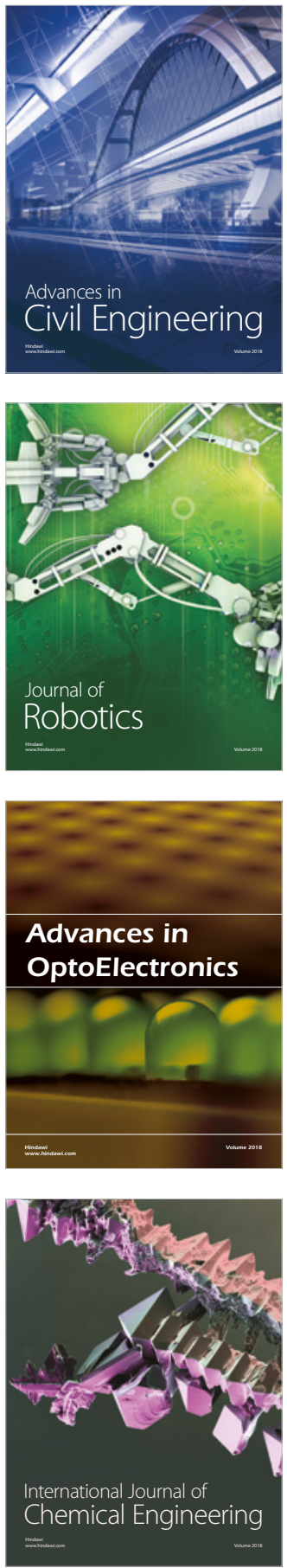

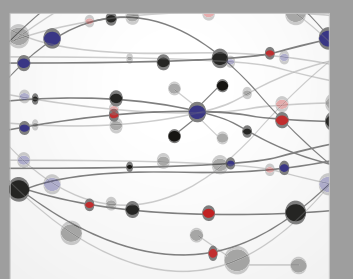

\section{Rotating \\ Machinery}

The Scientific World Journal

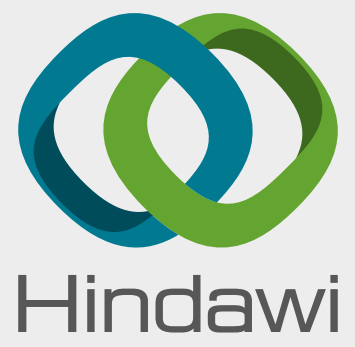

Submit your manuscripts at

www.hindawi.com
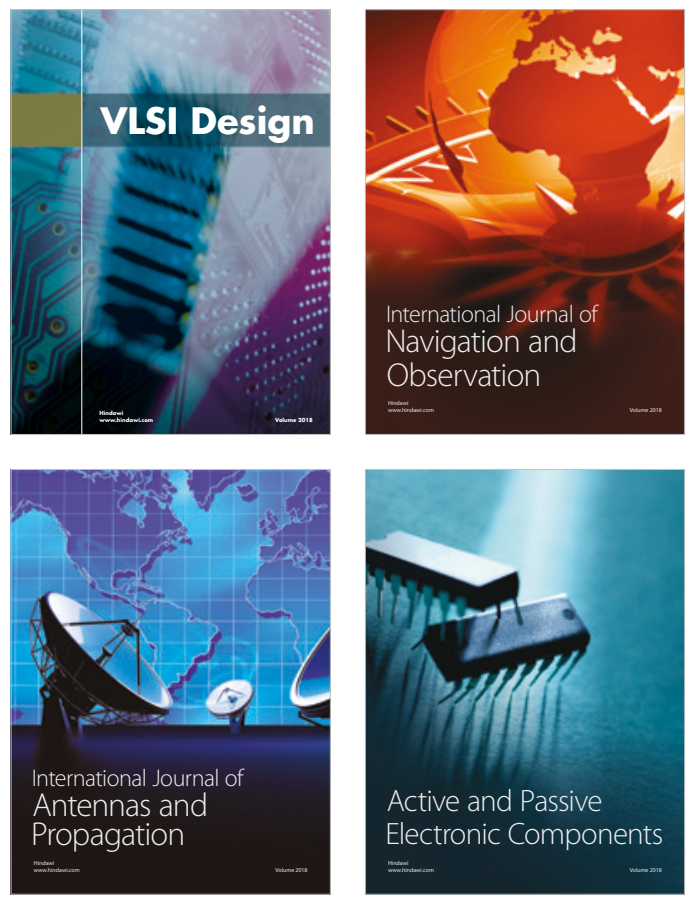
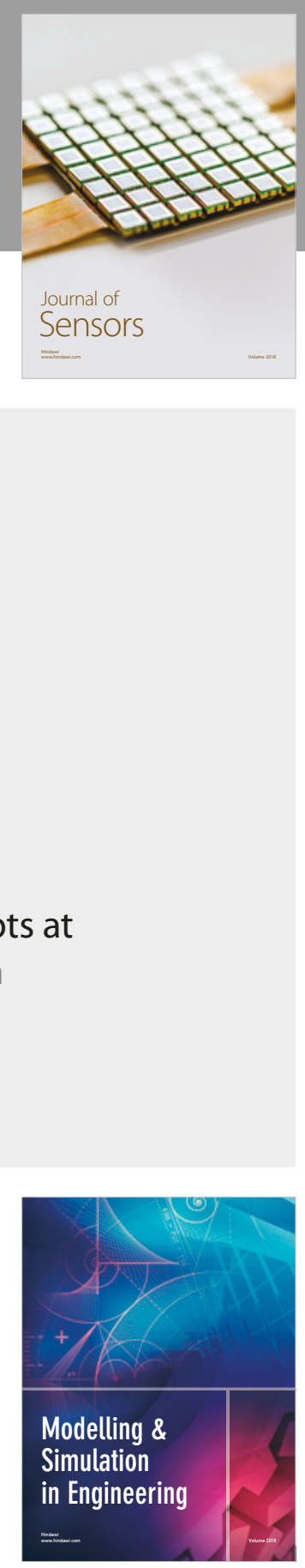

\section{Advances \\ Multimedia}
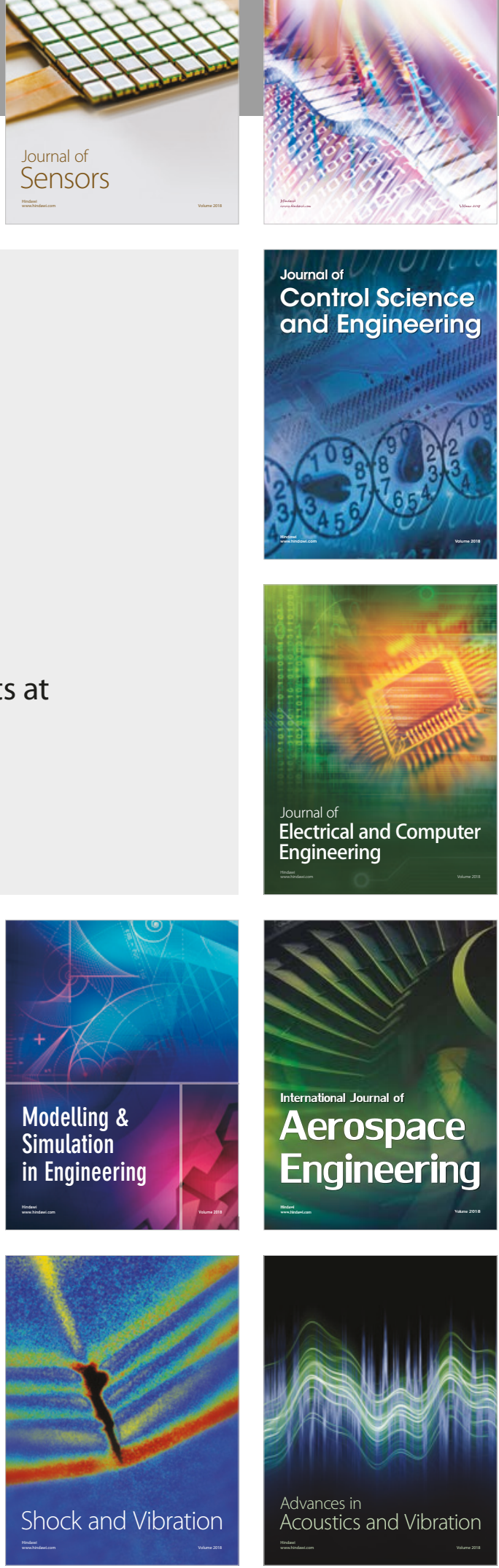